\title{
KEANEKARAGAMAN JENIS MANGROVE DI DESA MENDALOK KECAMATAN SUNGAI KUNYIT KABUPATEN MEMPAWAH
}

\author{
(Diversity of mangrove at Mendalok village Sungai Kunyit subdistrict Mempawah regency)
}

\author{
Syahrul Muharamsyah, M Sofwan Anwari, Hafiz Ardian \\ Fakultas Kehutanan Universitas Tanjungpura Jalan Daya Nasional Pontianak 78124 \\ Email: muharamsyahsyahrul@gmail.com
}

\begin{abstract}
Mangrove forests are unique ecosystems that have ecological, biological and socio-economic functions. The function of mangrove forests on the environment is very important especially in the coastal and oceanic regions. Mangrove forests providers of wood, leaves as raw material for medicines, and natural dye. This study aims to inventory the diversity of species of mangrove vegetation in Mendalok Village, Sungai Kunyit Subdistrict, Mempawah Regency. The benefits of this study are to provide the data on mangrove forest vegetation as basic data for local government and related agencies in efforts to protect and preserve mangrove forests in Mendalok Village, Sungai Kunyit Subdistrict, Mempawah Regency. Inventory the tree in mangrove forest used a line with measured 200 meters. There are 6 lines and the distance between the lines as far as 100 meters. The lines of observation are placed by purposive sampling. The results of research found 11 types of species and consisted of 6 genera. The genera are Avicennia, Bruguiera, Ceriops, Rhizophora, Soneratia and Xylocarpus. The species found were Avicennia alba, Avicennia marina, Bruguiera cylindrica, Bruguiera gymnorrhiza, Bruguiera parviflora, Ceriops decandra, Rhizophora apiculata, Rhizophora mucronata, Rhizophora stylosa, Sonneratia caseolaris, Xylocarpus mollucensis. Diversity of mangrove species in Mendalok Village, Sungai Kunyit Subdistrict, Mempawah Regency was high and should be maintained for conservation and ecotourism area.
\end{abstract}

Keywords : conservation, ecotourism, mangrove, Mendalok Village

\section{PENDAHULUAN}

Hutan mangrove merupakan suatu ekosistem yang mempunyai fungsi ekologis, biologis dan sosial ekonomi. Fungsi hutan mangrove terhadap lingkungan hidup sangat besar, mengingat hutan mangrove merupakan ekosistem utama pendukung kehidupan yang penting di wilayah pesisir dan lautan. Hutan mangrove juga memiliki fungsi ekonomis yang penting, seperti penyedia kayu, daundaunan sebagai bahan baku obat-obatan, dan lain-lain (Bengen, 2003). Provinsi Kalimantan Barat memiliki garis pantai sepanjang 1.163,3 Km yang membentang dari arah utara ke selatan. Sepanjang wilayah pesisir ini terdapat ekosistem mangrove yang dikenal oleh masyarakat sebagai hutan bakau dengan luas sekitar 40.000 Ha (Dinas Kelautan dan Perikanan Provinsi Kalimantan Barat, 2007). Hutan mangrove di Provinsi Kalimantan Barat tumbuh tersebar berkelompok di beberapa daerah yang mengandung lumpur di sepanjang pantai Muara Sungai Duri, Pantai Singkawang dan Pemangkat, Delta Sungai Kapuas, Bagian Selatan Muara Sungai Ambawang, Daerah Pulau Padang Tikar dan Pulau Maya, Daerah Sungai Kuala, serta Pantai Ketapang (Said, 2001). 
Hutan mangrove juga terdapat di Kecamatan Sungai Kunyit Kabupaten Mempawah. Salah satu desa yang ada di Kecamatan Sungai Kunyit yang mempunyai hutan mangrove adalah Desa Mendalok. Hutan mangrove yang berada di Desa Mendalok masih terjaga kealamiannya. Hal ini dapat dibuktikan dari observasi yang dilakukan, bahwa tumbuhan mangrove seperti Avicennia marina, Rhizophora stylosa, Bruguiera cylindrica banyak dijumpai dan tumbuh subur di daerah pesisir laut dan daratan. Keberadaan hutan mangrove di Desa Mendalok sangat penting untuk mencegah abrasi.

Hutan mangrove yang terdapat di daerah lain cenderung mengalami kerusakan dan berkurangnya luasan karena ditebang dan dialihfungsikan sebagai lahan budidaya ikan seperti di Desa Dabung Kabupaten Kubu Raya. Rusaknya hutan mangrove telah menim bulkan abrasi pantai dan merembesnya air laut ke lahan pertanian yang terjadi di sepanjang pesisir Sungai Duri dan Pemangkat. Hal tersebut berbeda dengan kenyataan yang ada di Desa Mendalok, dimana hutan mangrovenya tumbuh dengan subur dan kawasan pesisirnya selalu mengalami penambah an daratan dari tahun ke tahun. Pengelolaan kawasan hutan mangrove sangat penting dilakukan, karena besarnya manfaat ekosistem mangrove, baik secara ekologi maupun secara ekonomi bagi masyarakat di Desa Mendalok. Sampai saat ini belum ada informasi mengenai keberagaman jenis vegetasi yang tumbuh subur sesuai zonasi hutan mangrove di Desa Mendalok. Penelitian ini bertujuan untuk mendapatkan data keanekaraga man jenis vegetasi mangrove di Desa Mendalok Kecamatan Sungai Kunyit Kabupaten Mempawah.

\section{METODE PENELITIAN}

Penelitian dilaksanakan di kawasan hutan mangrove Desa Mendalok Kecamatan Sungai Kunyit Kabupaten Mempawah dengan luas hutan 14,22 Ha. Waktu untuk penelitian dan analisis data dilakukan selama lebih kurang 4 (Empat) minggu, mulai tanggal 2 sampai 30 April 2018.

Metode yang digunakan dalam penelitian adalah metode jalur berpetak (Soerianegara dan Indrawan, 1978). Petak pengamatan diletakkan secara Purposive Sampling, dengan asumsi vegetasi yang ada dapat mewakili seluruh komunitas vegetasi di kawasan mangrove Desa Mendalok. Pada kawasan hutan mangrove diambil 6,67\% (Mukhlisi, 2013) sehingga dari luasan total semula yang berukuran 14,22 Ha menjadi 0,94 Ha dan dibulatkan menjadi $1 \mathrm{Ha}$.

Lokasi yang diteliti dibuat 6 jalur dengan lebar $10 \mathrm{~m}$ dan panjang $200 \mathrm{~m}$, pada jalur sub-petak ukur dengan ukuran $2 \times 2 \mathrm{~m}$ untuk semai, 5x5m untuk tingkat pancang, dan untuk tingkat pohon dengan ukuran 10x10m. Pencatatan data menggunakan Tally sheet berbagai jenis pohon pada kawasan hutan mangrove. Petak pengamatan di lapangan dengan meng gunakan plot jalur berpetak disajikan pada Gambar 1. 


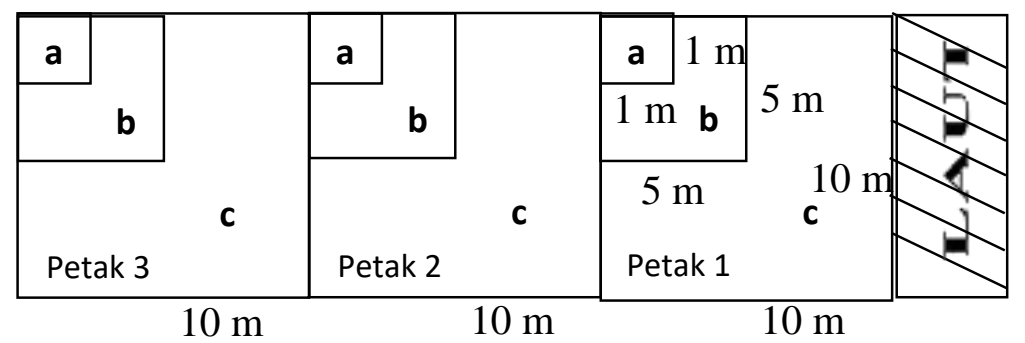

Gambar 1. Plot pengamatan vegetasi di hutan mangrove Desa Mendalok Kecamatan Sungai Kunyit Kabupaten Mempawah (plot observation of vegetation at Mendalok village, Sungai Kunyit subdistrict, Mempawah regency)

Peletakan jalur pengamatan berada tegak lurus arah laut. Jumlah jalur yang digunakan dalam penelitian ini adalah sebanyak 6 (enam) jalur, dengan panjang setiap jalur 200 meter. Jalur dibuat disebelah utara sungai sebanyak 1 buah dan disebelah selatan sungai sebanyak 5 buah, jarak antar jalur sejauh 100 meter. Analisis data yang didapat dari lapangan menggunakan rumus Indeks Nilai Penting (INP), Indeks Dominansi (C), Indeks Keanekaragaman Jenis (H') dan Indeks Kelimpahan Jenis (e). Jalur pengamatan disajikan pada Gambar 2.

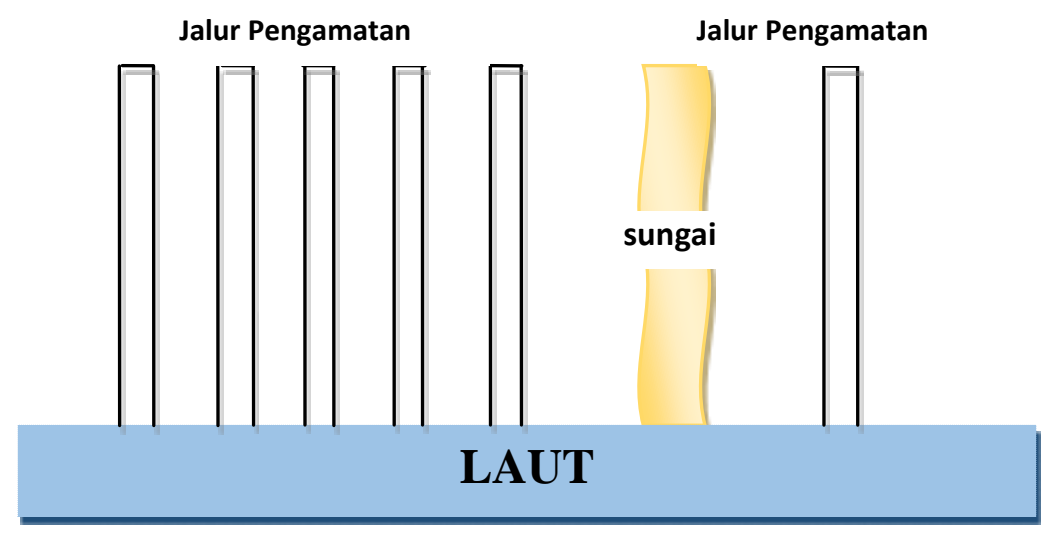

Gambar 2. Jalur pengamatan vegetasi di hutan mangrove Desa Mendalok Kecamatan Sungai Kunyit Kabupaten Mempawah (line observation of vegetation at Mendalok village, Sungai Kunyit subdistrict, Mempawah regency)

HASIL DAN PEMBAHASAN

Jenis vegetasi di hutan mangrove Desa Mendalok Kecamatan Sungai Kunyit Kabupaten Mempawah

Analisis vegetasi pada enam jalur penelitian yang masing-masing jalur memiliki panjang 200 meter dengan jarak antar jalur 100 meter mendapatkan sebanyak 11 jenis spesies pohon mangrove. Spesies pohon mangrove yang ditemukan terdiri atas enam genus, yaitu genus Avicennia, Bruguiera, Ceriops, Rhizophora, Sonneratia dan Xylocarpus. Jenis-jenis vegetasi yang terdapat di kawasan hutan mangrove Desa Mendalok Kecamatan Sungai Kunyit Kabupaten Mempawah disajikan pada Tabel 1. 
Tabel 1. Jenis-jenis vegetasi mangrove yang terdapat di Desa Mendalok Kecamatan Sungai Kunyit Kabupaten Mempawah (Mangrove vegetation species at Mendalok Village Sungai Kunyit subdictrict Mempawah regency)

\begin{tabular}{|c|c|c|c|}
\hline No. & Genus & Jenis & Nama Daerah \\
\hline \multirow[t]{2}{*}{1.} & Avicennia & Avicennia alba Blume & Api-api \\
\hline & & Avicennia marina (Forsk.) Vierh. & Api-api putih \\
\hline \multirow[t]{3}{*}{2.} & Bruguiera & Bruguiera cylindrica (L.) Bl. & Tanjang \\
\hline & & Bruguiera gymnorrhiza (L.) Lamk & Tumu \\
\hline & & $\begin{array}{l}\text { Bruguiera parviflora (Roxb.) W.\& A. ex } \\
\text { Griff. }\end{array}$ & Lenggadai \\
\hline 3. & Ceriops & Ceriops decandra (Griff) Ding Hou & Tengi \\
\hline \multirow[t]{3}{*}{4.} & Rhizophora & Rhizophora apiculata BI. & Belukap \\
\hline & & Rhizophora mucronata Lmk. & Bakau kurap \\
\hline & & Rhizophora stylosa Griff. & Bakau \\
\hline 5. & Sonneratia & Sonneratia caseolaris (L.) Engl. & Pedada \\
\hline 6. & Xylocarpus & Xylocarpus moluccensis (Lamk) M. Roem. & Nyirih batu \\
\hline
\end{tabular}

\section{Indeks Nilai Penting (INP)}

Indeks nilai penting (INP) pada vegetasi tingkat semai yang tertinggi pada spesies Bruguiera cylindrica dengan nilai 81,70 diikuti oleh spesies Avicennia alba dengan nilai 63,23. INP pada vegetasi tingkat pancang yang tertinggi pada spesies Avicennia alba dengan nilai 56,81 diikuti oleh spesies
Bruguiera cylindrica dengan nilai 55,64 . INP pada vegetasi tingkat pohon yang tertinggi pada spesies Bruguiera cylindrica dengan nilai 115,61 dan diikuti oleh spesies Rhizophora apiculata dengan nilai 56,55. Nilai INP pada vegetasi tingkat semai, pancang dan pohon disajikan pada Tabel 2 . 
Tabel 2. Nilai Indeks Nilai Penting (INP) Jenis Vegetasi Tingkat Semai, Pancang, Pohon di hutan mangrove Desa Mendalok Kecamatan Sungai Kunyit Kabupaten Mempawah (Important Value Indeks (IVI) of seedlings, poles, and trees at mangrove forest of Mendalok Village Sungai Kunyit subdictrict Mempawah regency)

\begin{tabular}{|c|c|c|c|c|c|}
\hline \multirow{2}{*}{ No } & \multirow{2}{*}{ Genus } & \multirow{2}{*}{ Jenis } & \multicolumn{3}{|c|}{ INP } \\
\hline & & & Semai & Pancang & Pohon \\
\hline \multirow[t]{2}{*}{1.} & Avicennia & Avicennia alba & 63,23 & 56,81 & 4,23 \\
\hline & & Avicennia marina & 18,79 & 48,82 & 24,96 \\
\hline \multirow[t]{3}{*}{2.} & Bruguiera & Bruguiera cylindrica & 81,70 & 55,64 & 115,61 \\
\hline & & Bruguiera gymnorrhiza & - & 18,56 & 18,91 \\
\hline & & Bruguiera parviflora & - & 39,18 & 3,30 \\
\hline 3. & Ceriops & Ceriops decandra & - & 7,30 & 4,98 \\
\hline \multirow[t]{3}{*}{4.} & Rhizophora & Rhizophora apiculata & 13,29 & 31,84 & 56,55 \\
\hline & & Rhizophora mucronata & 14,25 & 25,96 & 43,70 \\
\hline & & Rhizophora stylosa & 8,68 & 5,85 & 3,99 \\
\hline 5. & Sonneratia & Sonneratia caseolaris & - & 9,98 & 13,87 \\
\hline \multirow[t]{2}{*}{6.} & Xylocarpus & Xylocarpus moluccensis & - & - & 9,84 \\
\hline & & TOTAL & 200,00 & 300,00 & 300,00 \\
\hline
\end{tabular}

Nilai indeks nilai penting (INP) tertinggi pada tingkat pohon dengan presentase 115,61 didominasi oleh jenis Bruguiera cylindrica yang ditemukan di 44 petak dari keseluruhan petak pengamatan. Hal ini berkaitan dengan karakteristik lingkungan tempat tumbuh sehingga jenis Bruguiera cylindrica dapat bertumbuh dengan baik dan mendominasi. Selanjutnya nilai INP pada tingkat pohon diikuti jenis Rhizophora apiculata dengan 56,55 dan Rhizophora mucronata dengan nilai 43,70. Kemudian dari 10 jenis vegetasi mangrove pada tingkat pancang yang ditemukan di lokasi penelitian, jenis Avicennia alba memiliki INP tertinggi dengan presentase 56,81. Hal ini dikarenakan tempat tumbuh Avicennia alba berada pada bagian depan pantai yang selalu dilalui pasang surut air laut. Jenis ini ditemukan di 37 petak pengamatan yang selanjutnya diikuti berturut-turut oleh jenis Bruguiera cylindrica 55,64 dan jenis Avicennia marina dengan presentase 48,82. Nilai INP untuk tingkat semai, dari 6 jenis yang ditemukan pada lokasi, jenis Bruguiera cylindrica yang memiliki INP tertinggi dengan presentase 81,70. Hal ini dikarenakan banyaknya vegetasi tingkat pohon jenis Bruguiera cylindrica yang tumbuh dengan baik. Selanjutnya diikuti oleh jenis Avicennia alba dengan 63,23 dan Avicennia marina 18,79.

\section{Indeks Dominansi (C)}

Indeks dominansi (C) merupakan parameter yang digunakan dalam suatu komunitas untuk menyatakan tingkat terpusatnya dominansi suatu spesies. Nilai indeks dominansi (C) jenis vegetasi tingkat semai tertinggi pada Bruguiera cylindrica dengan nilai 0,25 . pada tingkat pancang tertinggi jenis Avicennia alba dengan nilai 0,05 . pada tingkat pohon tertinggi jenis Bruguiera cylindrica 
dengan nilai 0,15 . Nilai indeks dominansi disajikan pada Tabel 3 .

Tabel 3. Nilai Indeks Dominansi (C) semai, pancang, dan pohon di hutan mangrove Desa Mendalok Kecamatan Sungai Kunyit Kabupaten Mempawah (Dominance Indeks of seedlings, poles, and trees at mangrove forest of Mendalok village Sungai Kunyit subdictrict Mempawah regency)

\begin{tabular}{|c|c|c|c|c|}
\hline \multirow{2}{*}{ No. } & \multirow{2}{*}{ Jenis } & \multicolumn{3}{|c|}{$\mathbf{C}$} \\
\hline & & Semai & Pancang & Pohon \\
\hline 1. & Avicennia alba & 0,11 & 0,05 & 0,00 \\
\hline 2. & Avicennia marina & 0,01 & 0,02 & 0,00 \\
\hline 3. & Bruguiera cylindrica & 0,25 & 0,02 & 0,15 \\
\hline 4. & Bruguiera gymnorrhiza & - & 0,00 & 0,00 \\
\hline 5. & Bruguiera parviflora & - & 0,04 & 0,00 \\
\hline 6. & Ceriops decandra & - & 0,00 & 0,00 \\
\hline 7. & Rhizophora apiculata & 0,00 & 0,00 & 0,04 \\
\hline 8. & Rhizophora mucronata & 0,00 & 0,00 & 0,02 \\
\hline 9. & Rhizophora stylosa & 0,00 & 0,00 & 0,00 \\
\hline 10. & Sonneratia caseolaris & - & 0,00 & 0,00 \\
\hline 11. & Xylocarpus moluccensis & - & - & 0,00 \\
\hline & TOTAL & $\mathbf{0 , 3 8}$ & 0,16 & $\mathbf{0 , 2 3}$ \\
\hline
\end{tabular}

Tabel 3 menujukkan nilai Indeks dominansi (C) tertinggi tingkat pohon adalah jenis Bruguiera cylindrica dengan nilai $(\mathrm{C}=0.15)$. Jenis tanjang ini mendominasi dengan tekstur tanah liat bercampur debu dan pasir yang padat, tempat tumbuhnya jarang tergenang pasang surut air laut, sehingga membuat jenis tanjang ini tumbuh subur pada zona belakang arah daratan. Nilai indeks dominansi untuk tingkat pancang yang mendominasi adalah jenis Avicennia alba dengan nilai $(\mathrm{C}=0.05)$. Hal ini dikarenakan pancang jenis Apiapi tumbuh subur di bagian depan pantai dengan tutupan tajuk yang rapat. Selanjutnya indeks dominansi tertinggi untuk tingkat semai adalah jenis Bruguiera cylindrica dengan nilai $(\mathrm{C}=0.25)$. Hal ini karena mendominasinya pohon jenis tanjang yang selalu membuat propagul secara terus menerus. Kondisi ini menunjukkan bahwa dari seluruh tingkatan, tidak ada penguasaan suatu jenis terhadap jenis yang lainnya dalam suatu komunitas, karena nilai indeks dominansi (C) yang didapat tidak ada yang mendekati 1, Oleh karena itu disimpulkan dari seluruh jalur pengamatan tidak ada jenis mengelompok pada tempat-tempat tertentu, yang berarti jenis-jenis vegetasi mangrove tersebut tersebar secara merata di dalam kawasan hutan mangrove.

\section{Indeks Keanekaragaman Jenis (H')}

Indeks keanekaragaman jenis merupa kan ciri tingkatan komunitas berdasar kan organisasi biologinya. Keaneka ragaman jenis atau spesies dapat diguna kan untuk menyatakan 
struktur komu nitas. Keanekaragaman spesies dapat digunakan untuk mengukur stabilitas komunitas, yaitu kemampuan suatu komunitas untuk menjaga dirinya tetap stabil meskipun ada gangguan terhadap komponenkomponennya (Soegianto, 1994). Keanekaragaman jenis vegetasi di hutan mangrove untuk semua tingkat, baik semai, pancang dan pohon tergolong rendah karena memiliki nilai $H^{\prime}<1$. Nilai total H' untuk semua jenis pada tingkat semai sebesar 0,63 , pada tingkat pancang nilai total $H^{\prime}$ sebesar 0,90 , dan pada tingkat pohon nilai total $\mathrm{H}^{\prime}$ sebesar 0,79. Hal ini diduga karena jumlah jenis vegetasi penyusun hutan mangrove Desa Mendalok masih belum banyak, yaitu sebesar 11 jenis vegetasi. Hutan mangrove di lokasi penelitian saat ini masih terus dilakukan penanaman oleh masyarakat untuk

Tabel 4. Nilai Keanekaragaman Jenis (H') dan Kelimpahan Jenis (e) (Type diversity index and Type abundance index)

\begin{tabular}{cccc}
\hline & Semai & Pancang & Pohon \\
\hline $\mathrm{H}$ & 0,63 & 0,90 & 0,79 \\
$\mathrm{e}$ & 0,81 & 0,90 & 0,76 \\
\hline
\end{tabular}

Indeks Kelimpahan Jenis (e)

Nilai Indeks kelimpahan jenis (e) digunakan untuk mengetahui pemerata an pembagian individu diantara jenis. Indeks kelimpahan jenis menunjukkan semakin tinggi nilai kelimpahan jenis maka penyebaran suatu jenis akan semakin merata dalam komunitas tersebut. Hal ini berfungsi untuk mengetahui keanekaragaman spesies penyusun vegetasi yang ada di dalam suatu kawasan. Hutan mangrove di upaya memperbanyak spesies pohonnya. Selanjutnya dari 11 jenis vegetasi yang ditemukan terdapat jenis Ceriops decandara yang berstatus rentan dan memerlukan perhatian khusus untuk pengelolaannya. Komposisi jenis penyusun vegetasi di hutan mangrove di Desa Mendalok lebih banyak dibanding kan komposisi jenis hutan mangrove di Tanam Nasional Bunaken Sulawesi Utara (Kaunang dan Kimbal 2009) dan di hutan mangrove di pesisir Kecamatan Sungai Raya Kabupaten Bengkayang yang diteliti oleh Yusuf (2012). Penelitian Yusuf (2012) hanya menemukan 8 jenis spesies pohon penyusun vegetasi hutan mangrove. Nilai indeks keanekaragaman jenis ( $\left.\mathrm{H}^{\prime}\right)$ hutan mengrove di Desa Mendalok disajikan pada Tabel 4. 
di hutan mangrove ini tidak sampai 1. Nilai total indeks kelimpahan jenis pada tingkat semai dengan nilai 0,81 . pada tingkat pancang sebesar 0,90 dan pada tingkat pohon sebesar 0,76 (Tabel 4). Jenis vegetasi penyusun hutan mangrove yang memiliki nilai indeks kelimpahan jenis (e) kurang dari 1 memiliki arti kelimpahan jenis mangrove masih tidak merata pada setiap areal atau kawasan hutannya. Hal ini sesuai dengan yang ditemukan dalam setiap petak yang diteliti, tidak setiap petak selalu memiliki jenis yang sama, dan juga pada setiap jalur tidak semua jalur memiliki jenis yang sama.

\section{Kesimpulan}

1. Jenis vegetasi yang ditemukan di kawasan hutan mangrove di Desa Mendalok Kecamatan Sungai Kunyit Kabupaten Mempawah adalah sebanyak 11 jenis.

2. Jenis mangrove yang memiliki INP tertinggi untuk tingkat semai di kawasan hutan mangrove Desa Mendalok adalah Bruguiera cylindrica dengan nilai INP sebesar 81,70 , untuk tingkat pancang jenis Avicennia alba dengan nilai INP sebesar 56,81 dan pada tingkat pohon INP terbesar terdapat pada jenis Bruguiera cylindrica dengan nilai INP sebesar 115,61.

3. Keanekaragaman jenis vegetasi di hutan mangrove untuk semua tingkat, baik semai, pancang dan pohon tergolong rendah karena memiliki nilai H' $<1$. Nilai H' pada tingkat semai sebesar 0,63, pada tingkat pancang nilai $\mathrm{H}^{\prime}$ sebesar 0,90 dan pada tingkat pohon nilai $\mathrm{H}^{\prime}$ sebesar 0,79 .

\section{Saran}

Hutan Mangrove di Desa Mendalok Kecamatan Sungai Kunyit Kabupaten Mempawah memiliki potensi tinggi sebagai areal konservasi dan ekoturisme sehingga diharapkan masyarakat dalam melakukan kegiatan penanaman dan rehabilitasi lahan dapat menanam jenis pohon mangrove yang sesuai pada setiap zonasi hutan mangrove yang sudah ada.

\section{DAFTAR PUSTAKA}

Atmawidjaja R. 1987. Konservasi dalam Rangka Pemanfaatan Hutan Mangrove di Indonesia dalam Prosiding Seminar III Ekosistem Mangrove. Proyek Penelitian Lingkungan HidupLIPI. Jakarta.

Bengen D. 2003. Pedoman Teknis Pengenalan dan Pengelolaan Ekosistem Mangrove. PKSPL. IPB. Bogor.

Dinas Kelautan dan Perikanan Propinsi Kalimantan Barat. 2007. Penetapan Kawasan Konservasi Mangrove dan Restoking Kepiting Bakau (Scylla serrata) di Pesisir Kabupaten Pontianak. Laporan Akhir Program Mitra Bahari. Dinas Kelautan dan Perikanan Kalimantan Barat.

Filian B I, Togar F M dan Muflihati. 2017. Komposisi dan Struktur Vegetasi Penyusun Zonasi Hutan Mangrove Tanjung Prapat Muda - Tanjung Bakau Kabupaten Kubu Raya. Jurnal Hutan Lestari 5 (1) : $104-112$. 
Mackinnon K, Hatta G dan Mangkalik A. 2000. Ekologi Kalimantan. Prenhallindo. Jakarta.

Nursal F dan Ismiati. 2005. Struktur dan Komposisi Vegetasi Mangrove Tanjung Sekodi Kabupaten Bengkalis Riau. Jurnal Biogenesis 2 (1): 1 - 7.

Prastomo R H, Herawatiningsih R, dan Latifah S. 2017. Keanekaragaman Vegetasi di Kawasan Hutan Mangrove Desa Nusapati Kabupaten Mempawah. Jurnal Hutan Lestari 5 (2) : 556 - 562.

Rizki, E Safitri, dan Asroen. 2015. Morfologi Bruguiera cylindrica yang Tumbuh di Hutan Mangrove Kecamatan Siberut Utara Kabupaten Kepulauan Mentawai. Jurnal Sainstek 7 (1) : 26 - 32.
Rusila N Y, Khazali M, dan Suryadiputra I N N. 1999. Panduan Pengenalan Mangrove di Indonesia. PHKA/WI-IP. Bogor.

Soerianegara I dan Indrawan A. 1978. Ekologi Hutan Indonesia. Fahutan IPB. Bogor.

Sudarmadji. 2003. Deskripsi Jenis-jenis Anggota Suku Rhizophoraceae di Hutan Mangrove Taman Nasional Baluran Jawa Timur. Biodiversitas 5 (2) : 66-70.

Suhardjono dan Rugayah. 2007. Keanekaragaman Tumbuhan Mangrove di Sepanjang Jawa Timur. Biodiversitas 8 (2) : 130 134. 